\title{
Monitoring of changes in trunk rotation during scoliosis physiotherapy Marianna Białek ${ }^{1}$, Andrzej M'hango*2 and Tomasz Kotwicki ${ }^{3}$
}

\author{
Address: ${ }^{1}$ BMK Functional Therapy, Wroclaw, Poland, ${ }^{2}$ Rehabilitation Center Terapeuta, Kielce, Poland and ${ }^{3}$ Department of Pediatric Orthopedics \\ and Traumatology, University of Medical Sciences, Poznan, Poland \\ Email: Andrzej M'hango* - terapeuta@kielce.home.pl \\ * Corresponding author
}

from 4th International Conference on Conservative Management of Spinal Deformities

Boston, MA, USA. 13-16 May 2007

Published: 12 October 2007

Scoliosis 2007, 2(Suppl I):S2 doi:10.I|86/|748-7|6I-2-SI-S2

This abstract is available from: http://www.scoliosisjournal.com/content/2/SI/S2

(C) 2007 Białek et al; licensee BioMed Central Ltd.

\section{Objective}

The aim of the study was to assess angle of trunk rotation (ATR) in primary scoliosis and in secondary curvatures in a cohort of adolescent girls during Functional Individual Therapy for Scoliosis (FITS) physiotherapy.

\section{Materials and methods}

Sixty-four girls with scoliosis (age $13.9 \pm 1.9$ years, mean Cobb angle $30.6 \pm 14.7$ degrees, Risser sign median 2.0), underwent a 14-day intensive in-patient physiotherapy program according to FITS. The monitoring of curve behavior was clinical, using the Bunnell scoliometer [1] to measure ATR. Measurements were performed in a relaxed and in actively corrected posture. Sum of rotation (SR) was calculated as equal to primary curve rotation (PCR) plus upper compensatory curve rotation (UCR) plus lower compensatory curve rotation (LCR). Fourteen girls were followed for one year, while undergoing outpatient FITS therapy and part-time (12 hours per day) brace treatment.

\section{Results}

Intensive in-patient FITS physiotherapy reduced primary curve rotation measured in a relaxed posture from $9.5 \pm$ 4.7 to $8.5 \pm 4.5$ degrees ( $\mathrm{p}=0.0004$, paired t test) as well as the sum of rotation from $13.1 \pm 6.7$ to $11.6 \pm 6.4$ degrees ( $p=0.0002$, paired t test). Trunk rotation in the upper compensatory curve was not affected ( $\mathrm{p}=0.11$, Wilcoxon matched-pairs test). Trunk rotation in the lower compensatory curve slightly increased from 0.9 to 1.7 degrees ( $p=0.0065$, Wilcoxon matched-pairs test). In actively corrected posture, PCR angle decreased from 8.2 \pm 4.3 to $7.2 \pm 4.6(\mathrm{p}=0.0063$, paired t test $)$, while SR angle decreased from $12.4 \pm 6.1$ to $11.4 \pm 6.0(\mathrm{p}=0.0054$, paired t test). In fourteen girls examined one year later in a relaxed posture there was no deterioration of the PCR angle (9.1 degrees versus 10.1 initially, $\mathrm{p}=0.16, \mathrm{NS}$ ) nor the SR angle (12.2 degrees versus 13.1 initially, $\mathrm{p}=0.18$, NS), while in the corrected posture the PCR angle decreased from $7.7 \pm 4.7$ to $5.6 \pm 3.4(\mathrm{p}=0.04$, paired $\mathrm{t}$ test) and the SR angle decreased from $11.4 \pm 5.4$ to $8.7 \pm$ 5.5 degrees ( $\mathrm{p}=0.04$, paired t test).

\section{Conclusion}

(1) We recommend to monitor ATR both in primary and in compensatory curves during scoliosis therapy. (2) Fourteen days' in-patient FITS therapy reduced trunk rotation in the primary curve and reduced the sum of rotations measured at three levels of the back, as well as increased the patient's capacity for active posture correction. (3) For patients who received out-patient exercises combined with half-time bracing, the result was stable after one year.

\section{References}

I. Bunnell WP: An objective criterion for scoliosis screening. J Bone Joint Surg 1984, 66A:138I-1387. 